\title{
Summary: Order and Disorder in Brains and Behavior
}

\author{
ADAM KePECS \\ Cold Spring Harbor Laboratory, Cold Spring Harbor, New York 11724, USA \\ Correspondence: kepecs@cshl.edu
}

\begin{abstract}
The 83rd Cold Spring Harbor Symposium on Quantitative Biology on Brains and Behavior: Order and Disorder in the Nervous System explored the tremendous recent progress in neuroscience and how these advances may be used to improve brain health and address psychiatric and neurological disorders. The Symposium explored a vast array of topics from cell types to cognition. My summary focuses on a few emerging themes. Innovative techniques were ever-present, opening up new experimental possibilities. The commoditization of many state-of-the-art technologies is pushing neuroscience beyond its artisanal ways. Another important theme was "circuits in the middle": Numerous presentations dissected cell type-specific circuits that connect different levels of analysis from molecules to behavior. These new technologies have enabled curiosity-driven investigations in animals to connect more directly with preclinical and clinical studies of human brain disorders. Numerous emerging approaches were presented in human neuroscience, bolstering the hope that circuit-specific manipulations will soon provide improved treatments for brain disorders.
\end{abstract}

The seat of the soul and the control of voluntary movement - in fact, of nervous functions in general-are to be sought in the heart. The brain is an organ of minor importance... .

—Aristotle, De motu animalium

Much has happened in neuroscience since Aristotle wrote these words. Progress in the past 4 years, since the previous Cold Spring Harbor Symposium dedicated to neuroscience, has been sufficiently rapid to warrant another meeting on the brain. The meeting on Cognition in 2014 took place after a gap of 18 years, and the changes in the field were evident in the novel approaches and excitement. There was a clear sense that we were at the dawn of a new era, and it was finally possible to study behavioral questions, even ones about cognition, at the level of neurobiology. That meeting was abuzz with an emerging suite of tools to target circuits, cell types, new types of measurement, and manipulations techniques. The BRAIN Initiative was just announced a year earlier and the enthusiasm for future possibilities was palpable.

Terry Sejnowski's stimulating summary of the previous symposium concluded that soon new techniques would enable us to uncover the biological mechanisms underlying thought, language, and other facets of cognitions that earlier appeared to belong to philosophy. His conclusions also foreshadowed the present symposium: "A new neurotechnology industry will be needed to translate these advances into medical devices that can alleviate suffering from brain dysfunctions." In just 4 short years, one of the main surprises has been the degree to which new insights and technologies are being applied to study brain disorders. This change was due not only to a different mix of participants but also to the ways that new approaches have enabled curiosity-driven investigations into disorders of the brain.
The current symposium reflected the enormous diversity of the field of neuroscience, with approaches from engineering to psychology to molecular biology and model systems from flies, worms, and rodents to humans. The 65 oral presentations and 106 posters covered a broad array of topics, from the role of microRNAs in development and brain organoids to cognition in rodents and the neural basis of social behavior in primates, which I cannot attempt to represent fully here. Nor can I convey the exhilaration of progress, the impromptu personal conversations, and lively scientific exchanges that are unlikely to transpire at future virtual conferences conceived to curb the greenhouse gas emissions of conference travel (Parncutt and Meyer-Kahlen 2018). Instead, this summary is an attempt to capture a few emerging themes and the beginning of a new era for neuroscience and to speculate on emerging directions of the field. Although these themes allowed me to highlight many of the presentations, I must apologize to those presenters whose material is not included as a consequence of the condensation of this unusually diverse Symposium.

\section{NOVEL TECHNOLOGIES DRIVE PROGRESS IN NEUROSCIENCE}

\begin{abstract}
[It] was there, ... that for the first time I had an opportunity to admire ... those famous sections of the brain impregnated by the silver method of the Savant of Pavia. - Santiago Ramón y Cajal
\end{abstract}

The groundbreaking research of Ramón y Cajal, arguably the father of modern neuroscience, was enabled by the latest neuron-targeting technology, the Golgi silver stain, and the latest-generation microscope, obtained from Carl Zeiss personally. Technology has driven progress in neuroscience for centuries and with unusual speed over the past decade.

(C) 2018 Kepecs. This article is distributed under the terms of the Creative Commons Attribution-NonCommercial License, which permits reuse and redistribution, except for commercial purposes, provided that the original author and source are credited. 
Technological developments were on display throughout the entire meeting. Indeed, many of the technologies that have become standard over the past few years would have belonged to science fiction just a few years prior.

\section{Linking Levels with Technologies}

The core challenge of neuroscience has been to build bridges across levels of analysis to determine how specialized cells - neurons-form networks and systems that then produce behavior. Until recently it has been challenging to link levels experimentally. A researcher might have been able to measure a few neurons at a time during behavior or take slices out of a brain to identify neuron types, but it was not possible to do all of this at once, connecting a single neuron to a circuit, a system, and behavior.

A common thread across many presentations was the use of new techniques to do all of this in a single animal: manipulation of molecularly defined circuits, turning circuit elements on or off, and increasingly sophisticated behavioral paradigms. Mice ruled the symposium, to their peril; they emerged as the critter of choice, reflecting the technological opportunities of today. We heard a fascinating array of talks about rodent behavior and circuit mechanisms, from David Anderson, Pico Caroni, Ann Churchland, Yang Dan, Joshua Gordon, Hailan Hu, Guoping Feng, Anatol Kreitzer, Bo Li, Zach Mainen, Rob Malenka, Nirao Shah, Karel Svoboda, Kay Tye, and Linda Wilbrecht. Technologically, all these speakers highlighted different facets of what is possible, but essentially all of them used multiple technologies that just a few years ago would have seemed to be individually astonishing.

\section{Emerging Approaches: Dish, Fish, and Human Neuroscience}

Observing neural activity across an entire brain at cellular resolution has long been a dream for neuroscientists. The small size and transparency of zebrafish larvae, along with genetically encoded activity sensors and new microscopy techniques, have made this fantasy a reality (Prevedel et al. 2014; Tomer et al. 2015; Allalou et al. 2017). At the meeting, Karl Deisseroth, Ed Boyden, and Fatih Yanik presented distinct microscopy techniques to reveal the dynamics of entire zebrafish brains. Ed Boyden also discussed exciting new voltage sensors enabling fast-tracking of activity dynamics (Piatkevich et al. 2018).

Improved neuroanatomical tracing methods have yielded numerous insights. We heard about progress on two compelling new anatomical approaches. Ed Boyden showed off the new expansion microscopy approach for enlarging brains ex vivo using an expandable polymer structure (think disposable diapers) and then allowing researchers to use standard microscopy to image them at nanoscales (Chen et al. 2015). Tony Zador presented another intriguing approach, converting the problem of mapping connections to a sequencing problem and showed his latest results with mapping long-range cortical connections by virally barcoding neurons (Zador et al. 2012).
Gaining molecular insights into human brains requires new experimental models. We heard from Flora Vaccarino and Sergiu Paşca about human brain organoids, brains grown in a dish from human cells that are coaxed into mimicking the structure of human brains (Amiri et al. 2018; Paşca 2019). These in vitro human brain models are exceptionally promising to identify developmental processes that previously could not be modeled in a dish and for modeling brain disorders-for instance, by producing organoids from patient-derived cells.

Another theme was new technologies for human neuroscience that will finally permit us to connect basic neuroscience knowledge with the human condition. Fatih Yanik showed implantable grid arrays for recording spikes from the cortical surface without penetrative implants. We also heard several presentations about a promising modality-ultrasound. Kim Butts Pauly showed direct brain activation and drug delivery by disrupting the bloodbrain barrier. Even more revolutionary techniques, presented by Yanik and Butts Pauly, promise to ultrasonically uncage drugs deep in the brain (Wang et al. 2018). These methods are likely to revolutionize neuroscience and enable circuit-specific pharmacology in humans, an incredible feat. Read Montague also discussed improvements in fast cyclic voltammetry, enabling simultaneous measurement of catecholamine and serotonin during behavior in patients undergoing neurosurgery (Montague and Kishida 2019).

\section{COMMODITIZATION OF STATE-OF-THE-ART TECHNOLOGIES}

\author{
More than iron, more than lead, more than gold I need \\ electricity. \\ I need it more than I need lamb or pork or lettuce or \\ cucumber. \\ I need it for my dreams.

$$
\text { - Racter, a computer program }
$$ \\ (Chamberlain 1984)
}

Computer programs have been able to write poetry for decades now, but for the time being, scientists are still necessary to write grants and papers. Perhaps the most striking technological aspect of the meeting was how techniques that appeared to be science fiction a decade ago and bleeding-edge just a few years back have become commodities, available off the shelf for anyone to use. The use of multiple state-of-the-art technologies to address questions reflects the new reality that their combination enables us to provide new kinds of answers. The combination of multiple tools used in individual presentations was often dizzying but also almost expected nowadays: Begin with the viral tracing of circuits, follow up with single-cell RNA sequencing, read activity via calcium or voltage with the latest multiphoton microscope, and then write back or delete activity with optogenetic actuators. $\overline{\text { Such }}$ tra-sh-read-write approaches were standard fare at the symposium.

The transition of bleeding-edge techniques to commodities is welcome news, a sea change from the often-artisanal ways of neuroscience labs compared to other fields 
of biology. One clear consequence of the commoditization of technologies is how it enhances experimental reliability and enables sharing. Until recently many of the nonmolecular subdisciplines of neuroscience often required artisanal knowledge and skills. Many techniques demanded substantial expertise, even bravado, such as patch electrode recordings of presynaptic boutons (Geiger and Jonas 2000). Some incredible feats were so challenging that few people could reproduce them, causing individual laboratories to specialize in specific approaches and technologies. These artisanal procedures are rapidly giving way to commodity technologies, enabling us to reproduce each other's results, share techniques and data, and boost progress in the field.

Technological commoditization presents numerous opportunities for neuroscience research, from new funding models to solving reproducibility problems. In molecular biology, next-generation technologies have already commoditized high-throughput DNA and RNA sequencing, giving access to individual laboratories without nearby genome centers. Similar changes in advanced imaging tools are revolutionizing neuroscience. Even state-of-theart data analysis has the potential to move to the cloud (Vogelstein et al. 2016). As a consequence of these developments, almost anyone can pick up the hottest, just-published paper, the stuff of dreams just a decade ago, reproduce it, and take it to the next level by extending its findings. For example, the transgenic mice might be ordered from Jackson Labs, viruses and plasmids from AddGene, and the software is hopefully available on GitHub. Parallel commoditization of the requisite knowledge is enhancing reproducibility and boosting progress. For instance, the initial characterization of the behavioral functions of midbrain dopamine neurons by Wolfram Schultz and colleagues took decades (Schultz et al. 2017), but the key insights can be now reproduced in an afternoon using fiber photometry, reporting bulk population activity, as attested in the presentations by Karl Deisseroth and Naoshige Uchida (Kim et al. 2016; Watabe-Uchida and Uchida 2019). However, not every technique will become as inexpensive and easy to deploy as fiber photometry. Advanced microscopy techniques have become too costly for even the best-funded labs, so future access will require expanded funding models for central cores as imaging discovery centers that push the technological envelope while providing broad access (Wallrabe et al. 2014).

\section{CROSS-SPECIES CONVERGENCE}

\section{Nothing in biology makes sense except in the light of evolution.

$$
\text { -Theodosius Dobzhansky }
$$

The meeting was dominated by rodent studies, primarily as a result of the technological possibilities. Nevertheless, an important emerging theme was cross-species convergence, from cell types to behavior. A broad range of species was represented, from flies, mice, rats, and monkeys to humans, enabling evolutionary comparisons. We saw all these species interrogated at multiple levels and heard about numerous convergent results across brain systems, circuits, and even cell types (Zelikowsky et al. 2019).

The possibilities of understanding the human condition at the cellular level were demonstrated in presentations by Ricardo Dolmetsch on patient-derived induced pluripotent stem cells as models of Dravet syndrome (Sun and Dolmetsch 2019) and by Flora Vaccarino and Sergiu Paşca on 3D organoids. These approaches facilitate relating neuron types across species at the transcriptomic level. Dravet syndrome, a severe pediatric epilepsy caused by a mutation in voltage-gated sodium channels, can now be studied using high-throughput approaches to screen for drugs in a dish with patient-derived cells, shown by Dolmetsch, in a transgenic fish model described by Yanik (Eimon et al. 2018).

We also saw convergences at the level of systems. Kay Tye presented captivating circuit results about observational learning in mice, focusing on the different output pathways of the anterior cingulate cortex (Allsop et al. 2018). These results resonated with previous human fMRI studies implicating anterior cingulate in action monitoring and social learning (Tremblay et al. 2017), including studies presented by Michael Platt on rhesus macaque social interactions (Jiang and Platt 2018).

We also saw convergent results for neuromodulators, such as dopamine and serotonin, representing ancient brain systems with evolutionarily preserved functions. There is increasing agreement about the core behavioral functions of dopamine across species as revealed in presentations from Naoshige Uchida and Read Montague. On the other hand, there was less clarity about the roles of serotonin in mice (Mainen, Malenka) and humans (Montague). The function of serotonin is precisely an area in which technical reproducibility is likely to pay dividends, and confusion is a prelude to understanding. We also heard about another ancient brainstem structure, the habenula, from Deisseroth in zebrafish and Hailan $\mathrm{Hu}$ in mice, outlining the common functions of this ancient brain structure.

Finally, even behavioral studies are converging in terms of techniques and results. In human studies, Daphna Shohamy presented behavioral strategies to separate episodic and reinforcement learning, Daniel Wolpert discussed statistical approaches to motor control, and Daniela Schiller described parametric tracking of social value. These sophisticated approaches are increasingly matched in nonhuman primates, such as studies of social value by Michael Platt, adolescent behavior in mice (Delevich et al. 2019), and quantitative rodent behaviors presented by Anne Churchland, Bo Li, Kay Tye, and myself (Ott et al. 2019).

\section{CURIOSITY-DRIVEN SCIENCE CONNECTS WITH THE CLINIC}

...all the most acute, most powerful, and most deadly
diseases, and those which are most difficult to be under-
stood by the inexperienced, fall upon the brain.
- Hippocrates, On the Sacred Disease

Arguably, the most intriguing emerging theme at the symposium was how curiosity-driven science is connect- 
ing with clinical conditions and needs. We heard many examples of this theme, often from investigators who were not taking this translational approach just a few years ago. Indeed, it appears that new and maturing technologies are opening scientific opportunities, with research driven by discovery-based instead of top-down incentives for preclinical studies.

Istvan Mody presented fresh results on neurosteroid control of $\mathrm{GABA}_{\mathrm{A}}$ receptors, following up on his influential work with Jamie Maguire showing that neurosteroidinduced dysregulation of specific $\mathrm{GABA}_{\mathrm{A}}$ subunits results in postpartum depression (Maguire and Mody 2008). Their groundbreaking studies in mice predicted the success of the recently FDA-approved allopregnanolone analog for postpartum depression by SAGE Therapeutics, the first new class of psychiatry drugs in decades (Kanes et al. 2017). Hailan Hu showed an impressive circuit dissection of the mechanisms underlying another new class of depression drugs-ketamine, revealing habenulaspecific actions of a broadly acting pharmacological agent (Yang et al. 2018; Cui et al. 2019). Antonello Bonci presented a captivating story of mouse-to-human translation. His initial mouse study showed that prolonged cocaine self-administration decreases the intrinsic excitability of pyramidal neurons in the prelimbic cortex (Chen et al. 2013). Through a series of fortuitous events, this research led to pilot studies in cocaine-addicted patients, revealing that transcranial magnetic stimulation (TMS) of dorsolateral prefrontal cortex reduces cocaine cravings and use (Madeo and Bonci 2019). Lui-hai Tsai presented a remarkable discovery that $40-\mathrm{Hz}$ visual flicker reduces amyloid $\beta$ in mouse models of Alzheimer's (Iaccarino et al. 2016). In an impressive presentation, she discussed ongoing human translational studies, paving the way for nonpharmacological treatments of dementia.

Several talks used mouse models of brain disorders generated using genetic manipulation techniques. Josh Gordon started by outlining the challenges and opportunities for biological psychiatry (Gordon et al. 2019). Akira Sawa went on to discuss the challenges of a genetics-first approach: Effect sizes for known psychiatric risk genes are very small, even for rare variants, and copy number variations with somewhat larger effect size may be important but not specific to a condition. He then presented insights into the role of an abundant microRNA, miRNA-124, in brain development and schizophrenia (Namkung et al. 2019). Rick Huganir discussed the molecular mechanisms underlying the effects of loss-of-function mutations in SYNGAP1 known to cause intellectual disability. Eric Nestler emphasized the use of new unbiased transcriptional approaches leading to the identification of "chromatin scars," which can produce lasting change in gene expression in brain reward regions, including nucleus accumbens, tracking the history of cocaine self-administration in mice (Mews et al. 2019). Rob Malenka showed that activating serotonergic dorsal raphe neurons could reverse social deficits in the $16 \mathrm{p} 11.2$ model (Klawonn and Malenka 2019), and Pico Caroni showed how the plasticity of inhibitory neurons underlies specific learning processes and reported that in $22 q 11$ deletion syndrome model mice, D2 receptor antagonists transiently rescue baseline and activation-induced parvalbumin plasticity in adult mice. Frances Edwards discussed improved transgenic mouse models of Alzheimer's disease that avoid the problems of overexpression models (Joel et al. 2019). These talks highlighted how it is possible to track down the molecular mechanisms and circuit impact of genetic insults and, in some cases, identify ways to rescue the resulting behavioral deficits.

Anatol Kreitzer presented a stimulating new direction: mapping dyskinesia genetics to a specific neuron type. Using a transgenic mouse model for periodic dyskinesia he showed that dystonia genes were enriched in indirect pathway medium spiny neurons, which enabled their circuit dissection approach, and rescue of stress triggered dystonia, highlighting the importance of cell type-specific genetics as a new way forward.

\section{BEYOND PHARMACOLOGICAL TREATMENTS IN HUMANS}

\begin{abstract}
The brain is not a bag of chemical soup, and it's a mistake to try to treat complex psychiatric disorders just by changing the flavor.

—David Anderson
\end{abstract}

The symposium also featured talks on new, nonpharmacological approaches to treating mental disorders in humans. The serendipitous discovery of drug treatments starting in the early 1950 s has not only helped patients but also dominated scientific approaches to biological psychiatry. Although neuroscience has embraced the idea that brain disorders are disturbances of neural circuits, moving beyond the chemical imbalance theory in practice requires new nonpharmacological treatment modalities.

We heard numerous examples of deep brain stimulation from Helen Mayberg and Andres Lozano. Although deep brain stimulation was initially approved for Parkinson's, Mayberg and Lozano discussed new brain targets showing promise for major depression, dystonia, mild cognitive impairment, and Alzheimer's disease (Lee and Lozano 2019). They discussed continuing the search for optimal targets - such as subgenual cingulate, ventral striatal region, and subthalamic nucleus-for different indications and the importance of patient selection to maximize success. A less-invasive but also less-specific technique, transcranial magnetic stimulation, has also been gaining ground in treating major depression and anorexia. Antonello Bonci discussed how his group moved from a mouse model of compulsive drug use to TMS stimulation of dorsolateral cortex for ameliorating cocaine craving and drug use (Chen et al. 2013; Madeo and Bonci 2019) and discussed several ongoing clinical trials building on their pilot studies. A continuing challenge for both DBS and TMS is the limited mechanistic understanding of their effects, a situation that is quickly changing.

Ultrasound, as discussed above, provides a range of new therapeutic modalities, presented by Pauly Butts and Yanik (Leung et al. 2019). Ultrasonic uncaging of drugs has the potential for an entirely new way of translating the circuitand cell type-specific insights - targeting neurons in se- 
lect brain regions. Quantitative behavioral approaches are also promising as a diagnostic tool, and we heard from Daniela Schiller about how to use social video games to quantify social cognition relevant to autism spectrum disorders (Tavares et al. 2015; Schafer and Schiller 2019).

\section{CONCLUSION: TOWARD SYSTEMS NEUROSCIENCE 2.0}

The era of systems neuroscience 2.0 is arriving: Brain monitoring and manipulation technologies are becoming commodities, allowing researchers to scale up experiments and integrate across levels of analysis in the same animal, connecting molecules to circuits to behavior. The impressive compendium of presentations at the symposium made it clear that neuroscience has reached this new stage. More new technologies will arrive, of course, including a few emerging ones we did not hear about, such as reporters for neuromodulators, and many tools will get better. Yet we have reached a threshold: Experiments crossing levels that could not have been imagined a decade ago are now common, in part because of a commoditization of technologies. This transformation is particularly important because artisanal ways are challenging to build on; once we can reproduce each other's results and take them to the next level, progress in neuroscience will accelerate.

Human neuroscience has historically been separate from neuroscience done in nonhuman animals. This situation is changing, as emerging technologies enable us to connect the human condition more directly with studies of animals. We heard about approaches at the genetic and cell type level: brain organoids, patient-derived neurons, and cell type-specific mapping of genetic disorders, forging strong connections between human and animal models. Another set of approaches builds bridges at the level of behavior. There is a lot of excitement about computational phenotyping of behavior in psychiatry, and the same strategies are beginning to be applied in animals (Kepecs and Mensh 2015). This approach provides a new point of convergence: algorithmically quantified behaviors with a computational dimensional approach to link human and animal studies. Finally, we need more ways to measure and manipulate human brains, such as the emerging invasive and noninvasive approaches to measuring spikes or neuromodulators beyond functional imaging, as well as manipulating the brain with ultrasound. These and other technologies hold the promise of entirely new ways of probing the human brain.

An important theme at the meeting was circuits in the middle. Although a broad range of presentations took molecular to behavioral approaches, many (and many more than previously) attempted to link these findings to cell type-specific circuits. Cell type-specificity is particularly important because as the definition of cell types iteratively evolves, it holds the potential to connect levels, from molecular and developmental studies to physiological and behavioral ones. Indeed, the definition of what is a cell type-specific circuit should be informed by multiple modalities of knowledge, from single-neuron sequencing to behavioral function (Fishell and Kepecs 2020).
These advances herald a neurobridge to the clinic, as we heard from numerous presentations in which curiositydriven discovery science led to clinically relevant insights and, in some cases, new treatments. The emergence of a true bridge to the clinic will provide critical mooring to neuroscience, currently in the trance of techniques. The field is possibly where cancer research was a few decades ago, when a researcher could study immune $\mathrm{T}$ cells and claim to study cancer, as the bridge from discovery science to the clinic was already visible. Indeed, that line of research led to immune checkpoint inhibitor drugs, among other things, helping cancer patients. At present, only the outlines of a similar bridge are visible for neuroscience.

As we heard at the meeting, biological psychiatry faces two daunting challenges. First, despite the substantial genetic component of many disorders, few if any highly penetrant variations have been identified that could provide a firm grounding for animal studies. Second, patients complain about their mental state, not their genetics or brain scans, so we need ways to quantify the subjective human mental experience. There is renewed hope that the genetics of mental disorders can be clarified by considering cell type-specific circuits, addressing the first challenge. This possibility could take many forms, from resolving human genetic observations into specific neuron types to using patient-derived neurons to study the convergence of diverse, small-effect genetic variations in defined cell type-specific circuits. On the flip side, the rigorous quantification of mental states holds the hope of a more objective classification of psychiatric disorders. Such specificity will likely feed back into an improved resolution for genetic analysis with better defined patient cohorts and also entirely new ways of linking with animal behavior: going beyond face validity - computational behavioral validity that rigorously links performance in algorithmic terms. These directions, as we heard from a number of investigators at the symposium, highlight how curiosity-driven neuroscience can provide new approaches for the understanding of disease states, in ways more common with other fields of biology. Finally, new techniques such as ultrasound hold the hope of noninvasive circuit-specific interventions, enabling fundamental neuroscience insights to be translated for clinical research.

Understanding the brain-how thoughts emerge from its specialized cells connected into complex networks-is arguably one of the greatest challenges of humanity. Therefore, it is no surprise that we are further away from understanding, especially actionable understanding to ameliorate brain disorders, than other fields of biology. The remarkable presentations at this symposium highlighted our rapid progress and thrilling possibilities, spurred by trailblazing technologies. The vast gap between the worlds of discovery neuroscience research and clinical research is narrowing. As experimental opportunities multiply and knowledge gaps close, I believe we have the responsibility as a community to build a bridge toward the clinic and provide a clear vision for how work at any level of analysis in neuroscience will contribute to an understanding of brain disorders. 


\section{REFERENCES}

Allalou A, Wu Y, Ghannad-Rezaie M, Eimon PM, Yanik MF. 2017. Automated deep-phenotyping of the vertebrate brain. Elife 6: e23379. doi:10.7554/eLife.23379.

Allsop SA, Wichmann R, Mills F, Burgos-Robles A, Chang CJ, Felix-Ortiz AC, Vienne A, Beyeler A, Izadmehr EM, Glober $\mathrm{G}$, et al. 2018. Corticoamygdala transfer of socially derived information gates observational learning. Cell 173: 13291342.e18. doi:10.1016/j.cell.2018.04.004

Amiri A, Copola G, Scuderi S, Wu F, Roychaudhury T, Liu F, Pochareddy S, Shih Y, Safi A, Song L, et al. 2018. Transcriptome and epigenome landscape of human cortical development modeled in organoids. Science 362: eaat6720. doi:10 $.1126 /$ science.aat 6720

Chamberlain W. 1984. The policeman's beard is half constructed: computer prose and poetry. Warner Books, New York.

Chen BT, Yau HJ, Hatch C, Kusumoto-Yoshida I, Cho HL, Hopf FW, Bonci A. 2013. Rescuing cocaine-induced prefrontal cortex hypoactivity prevents compulsive cocaine seeking. Nature 496: 359-362. doi:10.1038/nature 12024

Chen F, Tillberg PW, Boyden ES. 2015. Optical imaging. Expansion microscopy. Science 347: 543-548. doi:10.1126/science .1260088

Cui Y, Yang Y, Dong Y, Hu H. 2019. Decoding depression: insights from glial and ketamine regulation of neuronal burst firing in lateral habenula. Cold Spring Harb Symp Quant Biol 83: 036871. doi:10.1101/sqb.2018.83.036871

Delevich K, Thomas AW, Wilbrecht L. 2019. Adolescence and "late blooming" synapses of the prefrontal cortex. Cold Spring Harb Symp Quant Biol 83: 037507. doi:10.1101/sqb.2018.83 .037507

Dobzhansky T. 1973. Nothing in biology makes sense except in the light of evolution. Am Biol Teacher 35: 125-129. reprinted in 1983. In Evolution versus creationism (ed. Zetterberg JP). ORYX Press, Phoenix, AZ. doi:10.2307/4444260

Eimon PM, Ghannad-Rezaie M, De Rienzo G, Allalou A, Wu Y, Gao M, Roy A, Skolnick J, Yanik MF. 2018. Brain activity patterns in high-throughput electrophysiology screen predict both drug efficacies and side effects. Nat Commun 9: 219. doi:10.1038/s41467-017-02404-4

Fishell G, Kepecs A. 2020. Interneuron types as attractors and controllers. Annu Rev Neurosci doi:10.1146/annurev-neuro070918-050421

Geiger JR, Jonas P. 2000. Dynamic control of presynaptic $\mathrm{Ca}^{2+}$ inflow by fast-inactivating $\mathrm{K}^{+}$channels in hippocampal mossy fiber boutons. Neuron 28: 927-939. doi:10.1016/S0896-6273 (00)00164-1

Gordon JA, Frost Bellgowan JA, Lawhorn C, Scheinert RB. 2019. Challenges and opportunities in psychiatric neuroscience. Cold Spring Harb Symp Quant Biol 83: 037523. doi:10.1101/sqb.2018.83.037523

Iaccarino HF, Singer AC, Martorell AJ, Rudenko A, Gao F, Gillingham TZ, Mathys H, Seo J, Kritskiy O, Abdurrob F, et al. 2016. Gamma frequency entrainment attenuates amyloid load and modifies microglia. Nature 540: 230-235. doi:10.1038/ nature20587

Jiang Y, Platt ML. 2018. Oxytocin and vasopressin flatten dominance hierarchy and enhance behavioral synchrony in part via anterior cingulate cortex. Sci Rep 8: 8201. doi:10.1038/ s41598-018-25607-1

Joel Z, Izquierdo P, Salih DA, Richardson JC, Cummings DM, Edwards FA. 2019. Improving mouse models for dementia. Are all the effects in tau mouse models due to overexpression? Cold Spring Harb Symp Quant Biol 83: 037531. doi:10.1101/ sqb.2018.83.037531

Kanes S, Colquhoun H, Gunduz-Bruce H, Raines S, Arnold R, Schacterle A, Doherty J, Epperson CN, Deligiannidis KM, Riesenberg R, et al. 2017. Brexanolone (SAGE-547 injection) in post-partum depression: a randomised controlled trial. Lancet 390: 480-489.
Kepecs A, Mensh BD. 2015. Emotor control: computations underlying bodily resource allocation, emotions, and confidence. Dialogues Clin Neurosci 17: 391-401.

Kim CK, Yang SJ, Pichamoorthy N, Young NP, Kauvar I, Jennings JH, Lerner TN, Berndt A, Lee SY, Ramakrishnan C, et al. 2016. Simultaneous fast measurement of circuit dynamics at multiple sites across the mammalian brain. Nat Methods 13: 325-328. doi: $10.1038 /$ nmeth. 3770

Klawonn AM, Malenka RC. 2019. Nucleus accumbens modulation in reward and aversion. Cold Spring Harb Symp Quant Biol 83: 037457. doi:10.1101/sqb.2018.83.037457

Lee DJ, Lozano AM. 2019. Current status of deep brain stimulation for Alzheimer's disease: from chance observation to clinical trials. Cold Spring Harb Symp Quant Biol 83: 037440.

Leung SA, Webb TD, Bitton RR, Ghanouni P, Butts Pauly K. 2019. A rapid beam simulation framework for transcranial focused ultrasound. Sci Rep 9: 7965. doi:10.1038/s41598019-43775-6

Madeo G, Bonci A. 2019. Rewiring the addicted brain: circuitsbased treatment for addiction. Cold Spring Harb Symp Quant Biol 83: 038158. doi:10.1101/sqb.2018.83.038158

Maguire J, Mody I. 2008. GABA $\mathrm{A}_{\mathrm{R}}$ plasticity during pregnancy: relevance to postpartum depression. Neuron 59: 207-213. doi:10.1016/j.neuron.2008.06.019

Mews P, Walker DM, Nestler EJ. 2019. Epigenetic priming in drug addiction. Cold Spring Harb Symp Quant Biol 83: 037663. doi:10.1101/sqb.2018.83.037663

Montague PR, Kishida KT. 2019. Computational underpinnings of neuromodulation in humans. Cold Spring Harb Symp Quant Biol 83: 038166. doi:10.1101/sqb.2018.83.038166

Namkung H, Lee BJ, Sawa A. 2019. Causal inference on pathophysiological mediators in psychiatry. Cold Spring Harb Symp Quant Biol 83: 037655. doi:10.1101/sqb.2018.83 .037655

Ott T, Masset P, Kepecs A. 2019. The neurobiology of confidence: from beliefs to neurons. Cold Spring Harb Symp Quant Biol 83: 038794. doi:10.1101/sqb.2018.83.038794

Parncutt R, Meyer-Kahlen N. 2018. Semi-Virtual Conference Guidelines: strategies to improve accessibility, diversity, documentation, and sustainability. https://static.uni-graz.at/ fileadmin/veranstaltungen/music-psychology-conference2018/ documents/Semi Virtual Conference Guidelines.pdf

Paşca SP. 2019. Building three-dimensional human brain organoids. Nat Neurosci doi:10.1038/s41593-018-0107-3

Piatkevich KD, Jung EE, Straub C, Linghu C, Park D, Suk HJ, Hochbaum DR, Goodwin D, Pnevmatikakis E, Pak N, et al. 2018. A robotic multidimensional directed evolution approach applied to fluorescent voltage reporters. Nat Chem Biol 14: 352-360. doi:10.1038/s41589-018-0004-9

Prevedel R, Yoon YG, Hoffmann M, Pak N, Wetzstein G, Kato S, Schrödel T, Raskar R, Zimmer M, Boyden ES, et al. 2014. Simultaneous whole-animal 3D imaging of neuronal activity using light-field microscopy. Nat Methods 11: 727-730. doi:10.1038/nmeth.2964

Schafer M, Schiller D. 2019. The hippocampus and social impairment in psychiatric disorders. Cold Spring Harb Symp Quant Biol 83: 037614. doi:10.1101/sqb.2018.83.037614

Schultz W, Stauffer WR, Lak A. 2017. The phasic dopamine signal maturing: from reward via behavioural activation to formal economic utility. Curr Opin Neurobiol 43: 139-148. doi:10.1016/j.conb.2017.03.013

Sun Y, Dolmetsch RE. 2019. Investigating the therapeutic mechanism of cannabidiol in a human induced pluripotent stem cell (iPSC)-based cellular model of Dravet syndrome. Cold Spring Harb Symp Quant Biol 83: 038174. doi:10.1101/sqb.2018.83 .038174

Tavares RM, Mendelsohn A, Grossman Y, Williams CH, Shapiro M, Trope Y, Schiller D. 2015. A map for social navigation in the human brain. Neuron 87: 231-243. doi:10.1016/j.neuron .2015 .06 .011

Tomer R, Lovett-Barron M, Kauvar I, Andalman A, Burns VM, Sankaran S, Grosenick L, Broxton M, Yang S, Deisseroth K. 
2015. SPED light sheet microscopy: fast mapping of biological system structure and function. Cell 163: 1796-1806. doi:10.1016/j.cell.2015.11.061

Tremblay S, Sharika KM, Platt ML. 2017. Social decision-making and the brain: a comparative perspective. Trends $\operatorname{Cogn} \mathrm{Sci}$ 21: 265-276. doi:10.1016/j.tics.2017.01.007

Vogelstein JT, Mensh B, Häusser M, Spruston N, Evans AC, Kording K, Amunts K, Ebell C, Muller J, Telefont M, et al. 2016. To the cloud! A grassroots proposal to accelerate brain science discovery. Neuron 92: 622-627. doi:10.1016/j.neuron .2016.10.033

Wallrabe H, Periasamy A, Elangovan M. 2014. Microscopy core facilities: results of an international survey. Micros Today 22: 36-45. doi:10.1017/S1551929514000091

Wang JB, Aryal M, Zhong Q, Vyas DB, Airan RD. 2018. Noninvasive ultrasonic drug uncaging maps whole-brain function- al networks. Neuron 100: 728-738.e7. doi:10.1016/j.neuron 2018.10.042

Watabe-Uchida M, Uchida N. 2019. Multiple dopamine systems: weal and woe of dopamine. Cold Spring Harb Symp Quant Biol 83: 037648. doi:10.1101/sqb.2018.83 .037648

Yang Y, Cui Y, Sang K, Dong Y, Ni Z, Ma S, Hu H. 2018. Ketamine blocks bursting in the lateral habenula to rapidly relieve depression. Nature 554: 317-322. doi:10.1038/ nature 25509

Zador AM, Dubnau J, Oyibo HK, Zhan H, Cao G, Peikon ID. 2012. Sequencing the connectome. PLoS Biol 10: e1001411. doi:10.1371/journal.pbio.1001411

Zelikowsky M, Ding K, Anderson DJ. 2019. Neuropeptidergic control of an internal brain state produced by prolonged social isolation stress. Cold Spring Harb Symp Quant Biol 83: 038109. doi:10.1101/sqb.2018.83.038109 


\title{
Erratum
}

Cold Spring Harb Symp Quant Biol 83 (2018) doi: 10.1101/sqb.2018.83.038885

\section{Erratum: Summary: Order and Disorder in Brains and Behavior}

\author{
ADAm KePECS
}

After the first version of this article was published, several typographical errors were identified that were missed during the production process. We apologize for this oversight. In the current version of the article, these errors have been corrected as outlined below.

- In the sixth sentence of the abstract, the phrase "Numerous presentations dissected links to cell type-specific circuits" was corrected to "Numerous presentations dissected cell type-specific circuits."

- In the fourth sentence after the quote in the "Cross-Species Convergence" section, the phrase "We saw how all these species interrogated at multiple levels" was corrected to "We saw all these species interrogated at multiple levels."

- In the second sentence of the first paragraph in the "Conclusion: Toward Systems Neuroscience 2.0" section, the phrase "The impressive compendium presentations at the symposium" was corrected to "The impressive compendium of presentations at the symposium."

- In the third sentence of the fourth paragraph in the "Conclusion: Toward Systems Neuroscience 2.0" section, the phrase "The field, possibly where cancer research was" was corrected to "The field is possibly where cancer research was."

- In the second-to-last sentence of the fifth paragraph in the "Conclusion: Toward Systems Neuroscience 2.0" section, the phrase "in other fields of biology" was corrected to "with other fields of biology."

- In the first sentence of the sixth paragraph in the "Conclusion: Toward Systems Neuroscience 2.0" section, the phrase "specialized cells connected to complex networks" was corrected to "specialized cells connected into complex networks." 


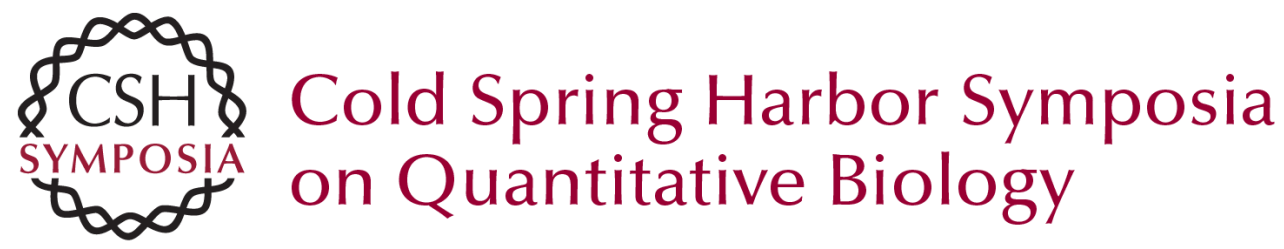

\section{Summary: Order and Disorder in Brains and Behavior}

Adam Kepecs

Cold Spring Harb Symp Quant Biol 2018 83: 219-225 originally published online July 29, 2019 Access the most recent version at doi:10.1101/sqb.2018.83.038885

\section{Related Content Erratum: Summary: Order and Disorder in Brains and Behavior Adam Kepecs \\ Cold Spring Harb Symp Quant Biol UNKNOWN , 2018 83:}

References This article cites 43 articles, 17 of which can be accessed free at: http://symposium.cshlp.org/content/83/219.full.html\#ref-list-1

Articles cited in:

http://symposium.cshlp.org/content/83/219.full.html\#related-urls

\section{Creative This article is distributed under the terms of the}

Commons

License

http://creativecommons.org/licenses/by-nc/4.0/, which permits reuse and redistribution, except for commercial purposes, provided that the original author and source are credited.

Email Alerting

Receive free email alerts when new articles cite this article - sign up in Service the box at the top right corner of the article or click here. 